\title{
Case studies of selected Project "Flash" events
}

\author{
K. A. Nicolaides ${ }^{1}$, S. C. Michaelides ${ }^{1}$, K. Savvidou $^{1}$, A. Orphanou ${ }^{1}$, P. Constantinides ${ }^{1}$, M. Charalambous ${ }^{1}$, and \\ M. Michaelides ${ }^{2}$ \\ ${ }^{1}$ Meteorological Service, Nicosia, Cyprus \\ ${ }^{2}$ Department of Lands and Surveys, Nicosia, Cyprus
}

Received: 13 January 2008 - Revised: 2 April 2008 - Accepted: 6 March 2009 - Published: 13 March 2009

\begin{abstract}
Flooding is a consequence of the prevailing meteorological situation, the intensity and duration of precipitation, geomorphology, human activities over a geographical region and other factors. Floods result in damage and destruction of infrastructure and private property and, in some cases, in fatalities. Flash floods are sudden and quite localized in extend, characterized by excessive amounts of rainfall within a short period of time and are distinguished from other floods by their degree of severity. The broader knowledge concerning flash floods is useful for the better understanding of the underlying thermodynamic and dynamic mechanisms, as well as the associated physical processes. The wider understanding of flashfloods can form part of an integrated system for short and very short forecasting of these events. In the present study, the synoptic, dynamic and thermodynamic conditions during the development of a baroclinic depression which affected the area of Cyprus on 6 November 2005 are studied. The depression was associated with extreme weather phenomena, such as thunderstorms, a water spout and high precipitation accumulations. The results indicate the importance of the dynamic parameters in the system's development and the thermodynamic analysis has shown the convective potential of the atmosphere.
\end{abstract}

\section{Introduction}

During the cold season, September to May, baroclinic depressions reach the area of Cyprus (El-Fandy, 1946; Kallos and Metaxas, 1980) mainly from the west (Michaelides et al., 2004; Nicolaides, 2005). Fewer depressions reach from other directions, while only few cases are generated or regenerated

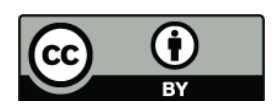

Correspondence to: K. A. Nicolaides (kleanthi@spidernet.com.cy) in situ (Michaelides et al., 2004; Nicolaides, 2005). Flood events are typical during the cold season and the main contributor is the associated baroclinic instability.

During the hot season, May to September, the area is under the influence of the Tibetan low and baroclinic depressions are very rare. Mean sea level pressure is relatively low, with marked high temperatures mainly inland; also, enhanced sea breezes penetrate several kilometers inland, thus acting as humidity transportation mechanisms during daytime. In the cases where thermal instability is increased, local thunderstorms are common with some of them resulting in flood events, mainly inland.

The present study outlines the methodology adopted in analyzing selected flood events in Cyprus that were submitted as case studies to the "Flash" project (European Union Sixth Framework Programme, Contract No. 036852). Case studies were selected on the basis of several common criteria, among which is the availability of appropriate data (e.g., radar and rainfall data from the Cyprus Meteorological Service and lightning data from the National Observatory of Athens). The selected Cyprus' events are the events on 6 November 2005, 17 to 19 November 2005 and 17 December 2005; for brevity, only the analysis of the first case (i.e., 6 November 2005) is presented. This event was chosen for study because, on the one hand, it can be characterized as a Cyprus cyclogenesis with quite high values in the vorticity field, and on the other hand, due to the severity of its associated weather phenomena. For instance, the resulted average precipitation for the whole island was very high, reaching $80 \%$ of its mean monthly value (the mean monthly precipitation for November is $53.3 \mathrm{~mm}$ ); also, high precipitation caused land sliding and flooding of some basements. The other two events were cases of upper and surface trough which invaded the Cyprus' area from the west, causing much localized flooding and minor damages.

Published by Copernicus Publications on behalf of the European Geosciences Union. 


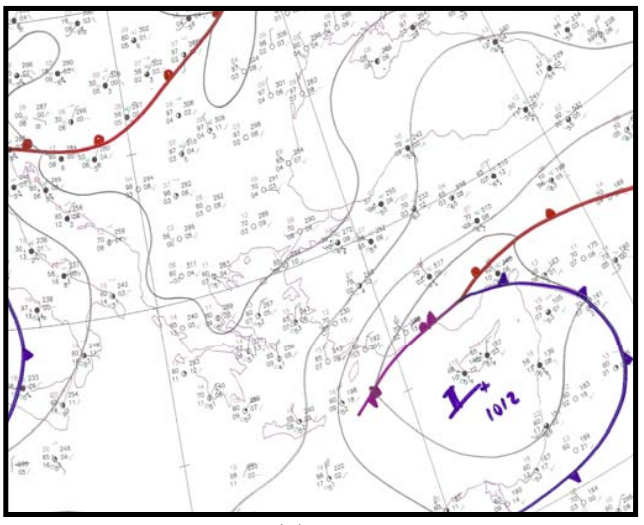

(a)

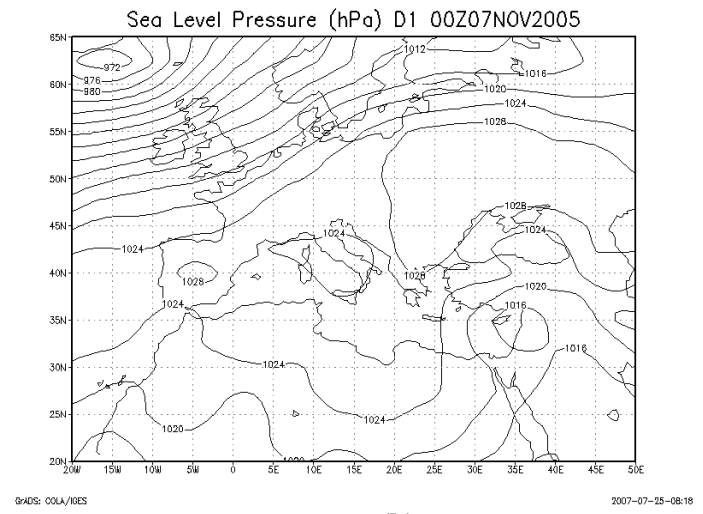

(b)

Fig. 1. (a) Surface synoptic analysis at 18:00 UTC 6 November 2005. (b) Sea level pressure at 00:00 UTC 7 November 2005.

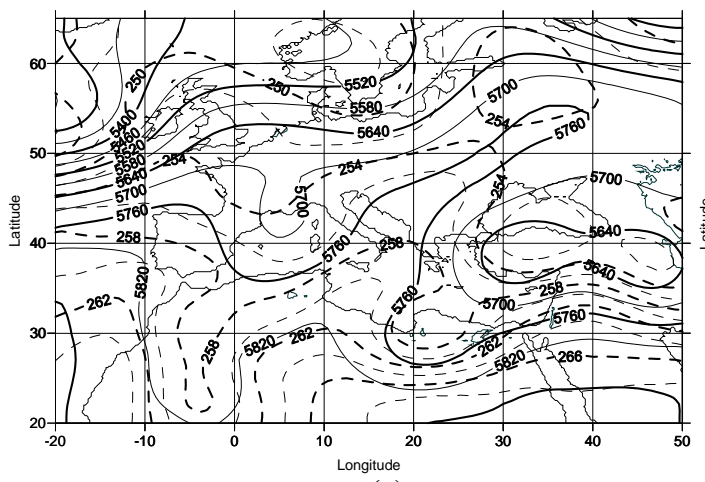

(a)

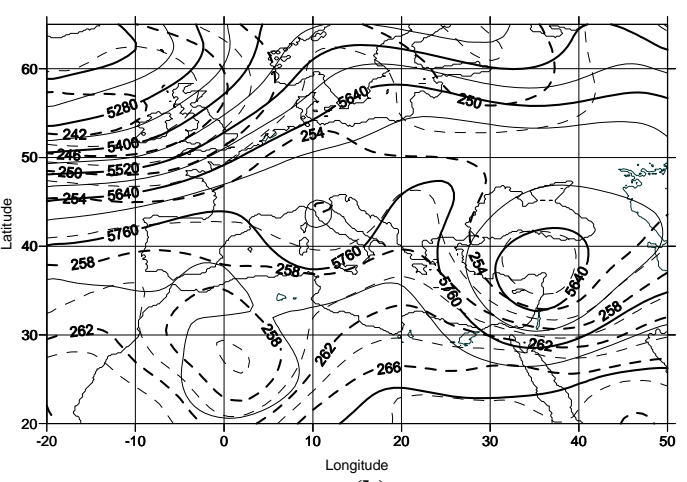

(b)

Fig. 2. $500 \mathrm{hPa}$ isobaric surface: geopotential height (solid lines, units: gpm) and temperature (dashed lines, units: K) at 00:00 UTC 6 (a) and 7 (b) November 2005.

\section{Data and methodology}

The present analysis includes an investigation concerning the synoptic, dynamic and thermodynamic behavior of the event. For the thermodynamic analysis, several thermodynamic indices and parameters were calculated, utilizing the radiosonde data from Athalassa synoptic station $\left(35^{\circ} 09^{\prime} \mathrm{N}\right.$, $33^{\circ} 24^{\prime} \mathrm{E}$ ) valid for 12:00 UTC. The indices and the parameters which are widely used and that are thought to characterize the thermodynamic state of the atmosphere are: the $\mathrm{KO}$ index, the K Index, the Total Totals Index (TT), the Convective Available Potential Energy (CAPE), the Bulk Richardson's Number (BRN), the Wet Bulb Zero degree isotherm (WBZ), the Cloud Top Temperature (CTT), the vertical extend of the convective cloud above freezing level (EL-FZ), the Vorticity Generation parameter (VGP) and the Convective Available Potential Energy in the lowest $3 \mathrm{~km}$ above the level of free convection (CAPE 0-x km) (for the mathematical formulation of these indices and parameters see University of Wyoming, 2008).
The dynamic parameters calculated and examined are the relative vorticity, the divergence of the horizontal wind vector, the distribution of the fields of temperature and geopotential height over the isobaric surfaces of $300 \mathrm{hPa}, 500 \mathrm{hPa}$ and $850 \mathrm{hPa}$, for the day before the event, the day of the event and the day after the event. The numerical forms of the relationships for calculating these parameters are given by Nicolaides et al. (2004). The data used for the calculations of the dynamic fields are the NCEP/NCAR global analyses for 00:00 UTC, with a grid length of $2.5^{\circ} \times 2.5^{\circ}$. The area of the calculations is bounded by the meridians $20^{\circ} \mathrm{W}$ and $50^{\circ} \mathrm{E}$ and the parallel circles $20^{\circ} \mathrm{N}$ and $65^{\circ} \mathrm{N}$. For the study of the event, the rainfall data that were used are taken from the network of the Cyprus Meteorological Service, consisting of 150 raingauges. Also, volume files and images from the Doppler C-band radar with a radial resolution of $500 \mathrm{~m}$ of the Meteorological Service were used. 
Table 1. Thermodynamic indices and parameters (see text for explanation).

\begin{tabular}{|c|c|c|c|c|c|c|c|c|c|c|}
\hline & $\mathrm{KO}\left({ }^{\circ} \mathrm{C}\right)$ & $\mathrm{K}\left({ }^{\circ} \mathrm{C}\right)$ & $\mathrm{TT}\left({ }^{\circ} \mathrm{C}\right)$ & $\begin{array}{l}\text { CAPE } \\
(\mathrm{J} / \mathrm{Kg})\end{array}$ & BRN & $\begin{array}{r}\text { WBZ } \\
(\mathrm{m})\end{array}$ & $\begin{array}{l}\text { CTT } \\
\left({ }^{\circ} \mathrm{C}\right)\end{array}$ & $\begin{array}{r}\text { EL-FZ } \\
(\mathrm{m})\end{array}$ & VGP & $\begin{array}{r}\text { CAPE } 0-\mathrm{x} \mathrm{km} \\
(\mathrm{J} / \mathrm{Kg})\end{array}$ \\
\hline $5 / 11 / 2005$ & 4.5 & 2.3 & 34.6 & & & 1879 & & & - & \\
\hline $6 / 11 / 2005$ & -2.6 & 23.9 & 44.3 & 550 & 10 & 2044 & -26 & 4439 & 0.166 & 260 \\
\hline $7 / 11 / 2005$ & -0.7 & 17.1 & 44.4 & & & 1909 & & & - & \\
\hline
\end{tabular}

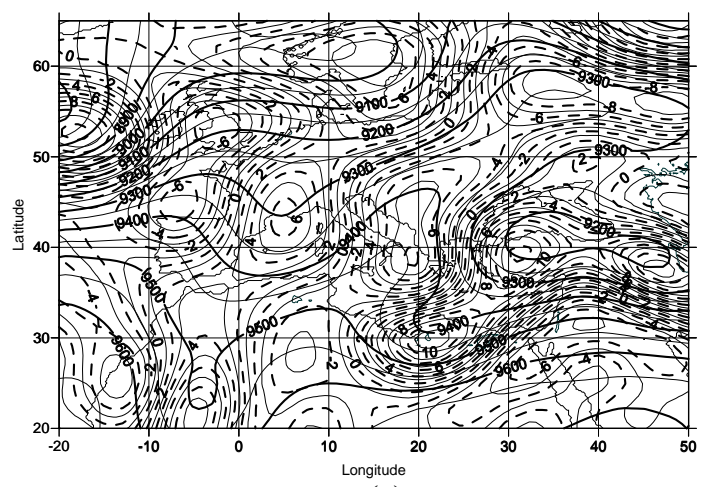

(a)

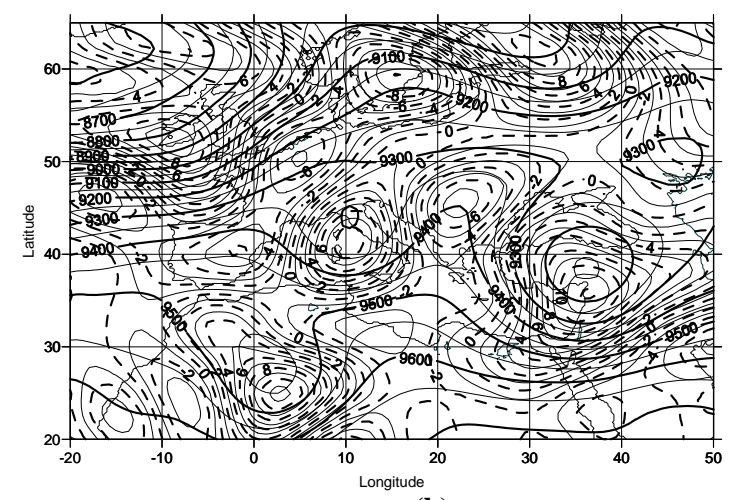

(b)

Fig. 3. $300 \mathrm{hPa}$ isobaric heights (solid lines) and relative vorticity (dashed and solid lines, units: $10^{-5} \mathrm{~s}^{-1}$ ) at $00: 00 \mathrm{UTC} 6$ (a) and 7 (b) November 2005.

\section{Synoptic study}

On 5 November 2005, the area of Cyprus was under the influence of a north-easterly flow, following the passage of a low pressure that affected the area on the previous day. The Siberian high extended through the Balkans up to northern coasts of Africa. The area between the east Black Sea and Middle East was affected by a weak low pressure. On 6 November, the northerly flow over Cyprus was disturbed, and a low pressure system, with its centre $(1012 \mathrm{hPa})$ south of Cyprus, was developed, accompanied by a warm and cold front (Fig. 1a). The low pressure moved to the east and on 7 November the area of Cyprus was again under the influence of a northerly flow (Fig. 1b).

On 5 November, at the isobaric surface of $500 \mathrm{hPa}$, the area of Cyprus was influenced by: a north-westerly flow, with an upper ridge to the west, covering the area from Central Mediterranean up to Russia; an upper low to the east, covering the area of the Black Sea and the Middle East; and a weak upper low over north Africa. On 6 November, the first upper low retrogressed and merged with the African one and, subsequently, affected the area of Cyprus. During the 24-h period, from 00:00 UTC on 6 November and 00:00 UTC on 7 November, the height and temperature at the $500 \mathrm{hPa}$ level decreased from 5660 to $5620 \mathrm{gpm}$ and from 257 to $252 \mathrm{~K}$, respectively (Fig. $2 \mathrm{a}$ and b). The position of the low at various levels strengthened the development of the low pressure system, while the enhanced decrease in the values of height and temperature from lower to higher levels increased the instability of the airmass.

\section{Dynamic study}

On 5 November, the distribution of the field of relative vorticity over the isobaric layer of $300 \mathrm{hPa}$ shows maximum values over the area of the upper low with a positive value of around $9 \times 10^{-5} \mathrm{~s}^{-1}$ over Cyprus. Due to negative vorticity advection, the value over Cyprus at 00:00 UTC on the following day noted a decrease, to around $6 \times 10^{-5} \mathrm{~s}^{-1}$ (Fig. 3a); at 00:00 UTC on the day after, it noted an increase, reaching a value of around $10 \times 10^{-5} \mathrm{~s}^{-1}$ (Fig. $3 \mathrm{~b}$ ), due to positive vorticity advection. The above values of the relative vorticity, as compared with the values of other cases of frontal depressions for the area of Cyprus, are quite high (Nicolaides et al., 2004).

The combination of positive vorticity advection over the area of Cyprus on 6 November from west and southwest, on the one hand, and the trough in upper levels having a northeast to southwest orientation, on the other hand, results in the surface low development over the area.

On 5 November and according to the distribution of the field of divergence of the horizontal wind vector over the isobaric surfaces of $850 \mathrm{hPa}$ and $300 \mathrm{hPa}$, the central and east Mediterranean are areas of low level divergence 


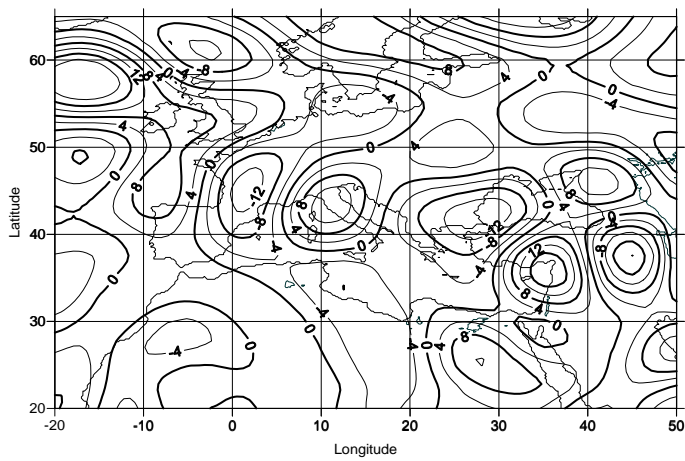

(a)

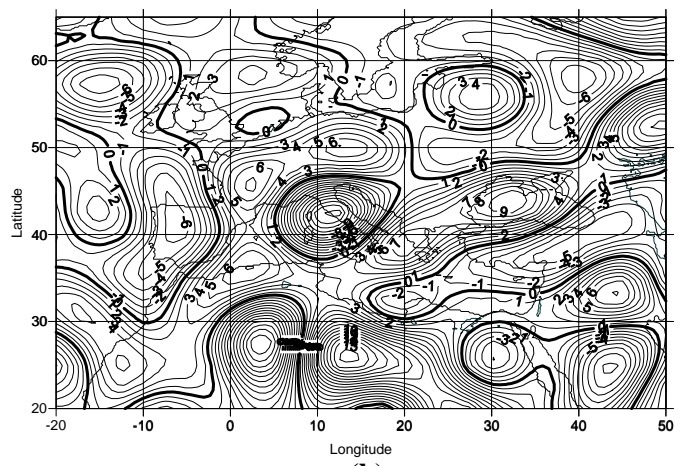

(b)

Fig. 4. Field of divergence of the horizontal wind vector over the isobaric surface of $300 \mathrm{hPa}\left(10^{-6} \mathrm{~s}^{-1}\right)$ (a) and $850 \mathrm{hPa}(\mathbf{b})$ for $00: 00 \mathrm{UTC}$ 6 November 2005.

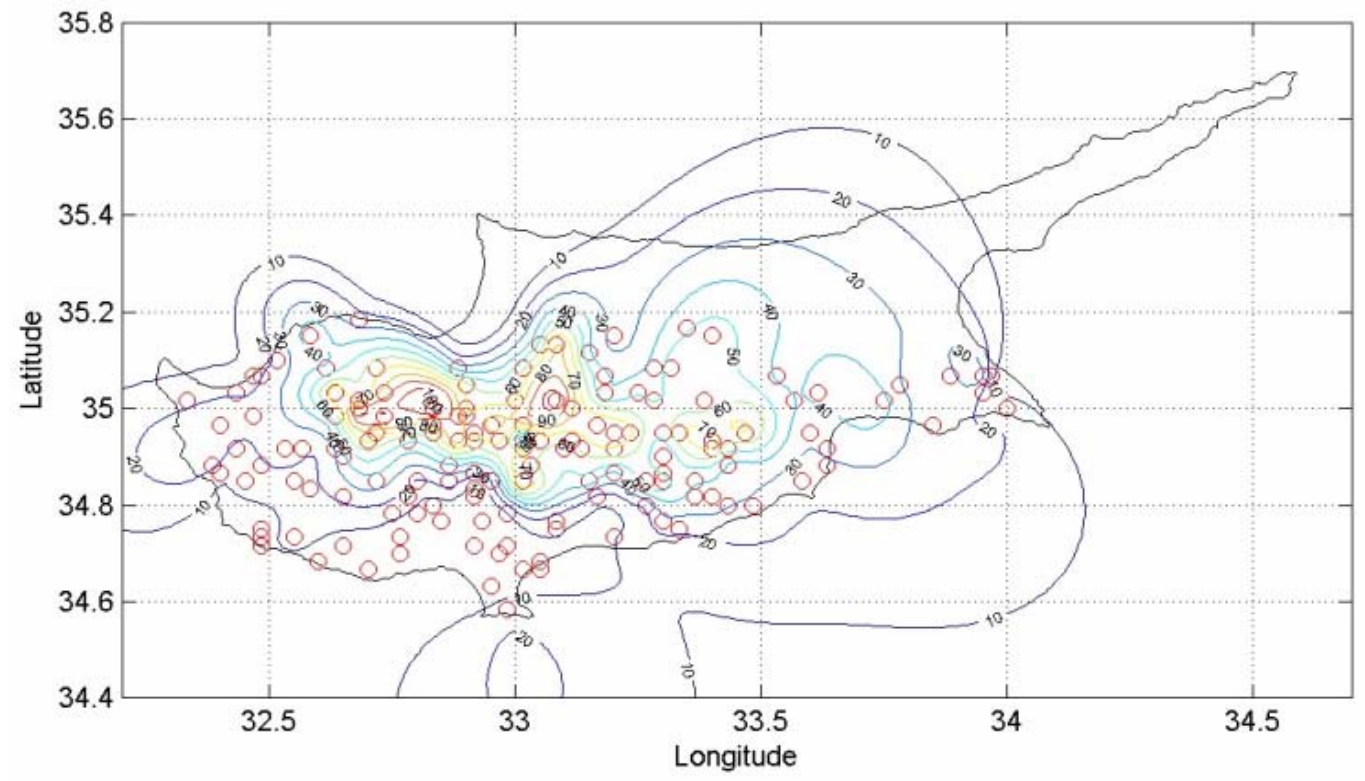

Fig. 5. Distribution of the daily precipitation amount for 6 November 2005.

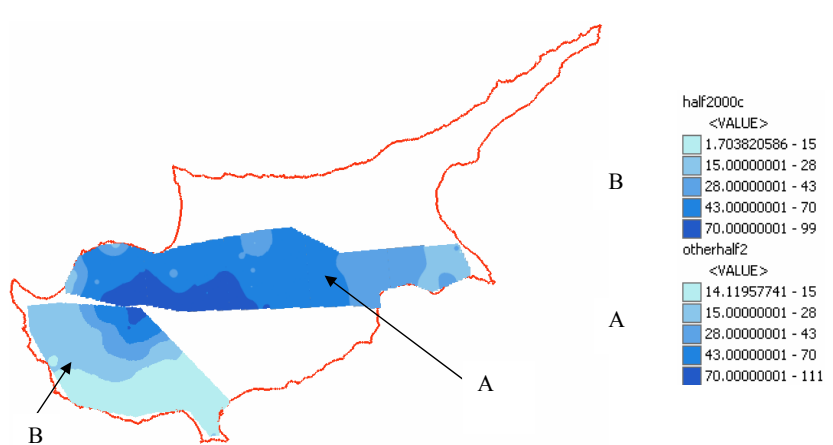

Fig. 6. Rainfall measured by rain gauges for 6 November 2005 .

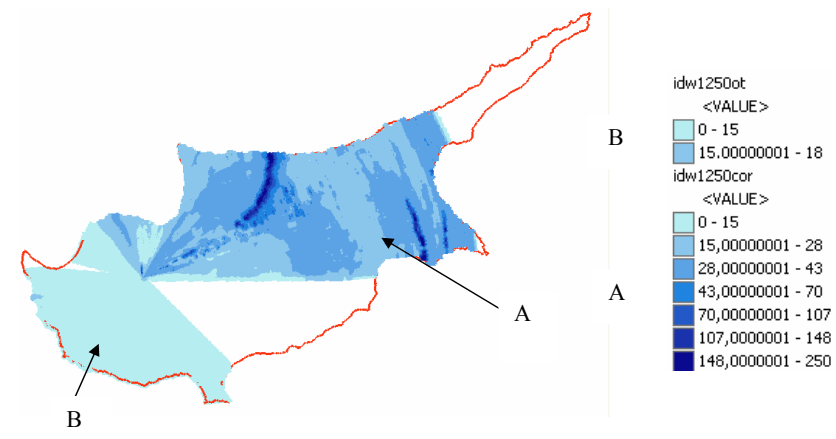

Fig. 7. Rainfall measured by radar for 6 November 2005 . 
(positive values) and upper level convergence (negative values). On 6 November, with the retrogression of the upper low system, the field of divergence noted a significant change: over Cyprus on the isobaric surface of $850 \mathrm{hPa}$, it changed from around $4 \times 10^{-6} \mathrm{~s}^{-1}$ to $-3 \times 10^{-6} \mathrm{~s}^{-1}$ (Fig. 4b) and on the isobaric surface of $300 \mathrm{hPa}$ it changed from around $-9 \times 10^{-6} \mathrm{~s}^{-1}$ to $15 \times 10^{-6} \mathrm{~s}^{-1}$ (Fig. 4a), thus leading to low level convergence and upper level divergence which subsequently enhances the ascending motion and the formation of cloud. On 7 November, the fields reversed their behavior having positive and negative values, respectively, increasing the stability of the airmass over the east Mediterranean

\section{Thermodynamic study}

The thermodynamic behavior of the atmosphere for the period between 3 and 9 November 2005 was also examined. The instability indices and parameters were calculated from the radiosonde at 12:00 $\mathrm{Z}$ at Athalassa station. All the indices (see Table 1, for 5, 6 and 7 November 2005) noted a significant increase on 6 November, indicating that the potential of the atmosphere to give thunderstorms increases with time.

Especially, the KO index and the CAPE $0-x$ km obtained values $-2.6^{\circ} \mathrm{C}$ and $260 \mathrm{~J} / \mathrm{kg}$, respectively which denote that the atmosphere had the potential to produce and sustain severe thunderstorms. The level of the Wet-Bulb zero isotherm was found at $2044 \mathrm{~m}$, denoting a moderate probability to give hail on the ground, justifying the recorded hail occurrence. The cloud top temperature and the vertical extend of the convective cloud above freezing level suggest small probability of thunderstorm. Also the Vorticity Generator Parameter suggests moderate probability for the development of a tornado, justifying the reported water spout south of Cyprus. According to Orphanou et al. (2007), the TT and the CAPE values denote a moderate potential of the atmosphere to give thunderstorms and hail while the $\mathrm{K}$ index value is considered as suggesting a high probability for thunderstorms.

\section{Associated weather phenomena}

The frontal behavior was associated with severe weather phenomena. The amount of cloud started to increase and became denser over Cyprus around 01:00 UTC on 6 November, while showery activity was recorded at all the raingauges of the Meteorological Service network during both the day and night; 40 raingauges measured 55 to $85 \mathrm{~mm}$ of rainfall in $24 \mathrm{~h}$ (Fig. 5), which is the threshold for which the Meteorological Service of Cyprus issues a YELLOW awareness level warning for EMMA (the warning system for severe weather of the Network of European Meteorological Services); 4 raingauges measured 85 to $115 \mathrm{~mm}$ of rainfall in $24 \mathrm{~h}$, which is the threshold for the ORANGE awareness level warning for EMMA over some areas, the intensity of rainfall was severe, with hourly precipitation rates around
$25 \mathrm{~mm}$. Recorded reflectivities by the Cyprus Meteorological Service radar reached $32 \mathrm{dBz}$ (which are nevertheless exceeded in other intense convective cases). Also, a water spout was reported $3 \mathrm{~km}$ east of Akrotiri station, on the south coast of the island. Although the accumulation amount of precipitation for the whole island was very high, reaching the $80 \%$ of the mean monthly precipitation, the problems that were caused were minor, because the highest amounts of rainfall were measured over high ground and rural areas. The surface observations from the three synoptic stations (Paphos, Akrotiri and Larnaka) showed that the maximum activity of the system was between 19:00 and 23:00 UTC that is a few hours before the passage of the surface low and the trough in the upper levels (Figs. 1b, 2b).

\section{Comparison between precipitation measured from raingauges and from radar}

To compare the accumulated precipitation measured by the rain gauge network and its estimation based on weather radar reflectivity the following relationship between rain rate $(R)$ and reflectivity $(Z)$ adopted:

$R=\sqrt[3]{\left(\frac{Z}{316}\right)^{2}}$

where, $R$ is in $\mathrm{mm} / \mathrm{h}$ and $Z$ is in $\mathrm{mm}^{6} \times \mathrm{m}^{-3}$. The above $Z / R$ relationship has been extensively tested in the "Voltaire" Project (funded by EU Fifth Framework Programme, Contract No. EVK2-CT-2002-00155) and gave good results (see Gabella et al., 2005, 2006). Figure 6 shows the rain gaugebased precipitation map for 6 November and Fig. 7 shows the corresponding radar-based precipitation map; the latter was constructed by averaging all hourly maps for the day resulting from the transformation of the reflectivity to rain by using Eq. (1) and then multiplying by 24 to get the spatial distribution of radar-derived precipitation in $\mathrm{mm} /$ day (both Figs. 6 and 7 were drawn with a Geographic Information System software, namely ArcGIS, adopting the Inverse Distance Weighted method - IDW). The comparison of the two precipitation maps was made in terms of two separate areas, separated by the shadowed regions due the Troodos mountain and Tripylos peak. The study areas are: area A (between $290^{\circ}$ and $95^{\circ}$, with respect to the radar site) and area B (between $140^{\circ}$ and $280^{\circ}$ ).

The precipitation spatial distributions shows that in part of area $\mathrm{A}$ in which both rain gauge and radar data are available, the precipitation resulting from the radar reflectivities is much higher than the precipitation measured by the raingauges over a small and narrow arc-shaped area to the northeast op the radar and over a narrow area to the southeast. Over the mountainous area of area A, the precipitation measured by the raingauges is higher than the radar estimations. Nevertheless, there are some areas where both the radar and 
rain gauge measurements are in very good agreement. In area $\mathrm{B}$, the precipitation measured by the rain gauges is higher mainly over the mountainous and semi-mountainous regions compared to the precipitation resulting from the radar estimations. On the plain areas, the two measurements are very similar.

The reasons for the above findings are: (a) the quality of the radar data is not sufficient and need appropriate treatment (see Einfalt and Michaelides, 2008; (b) the two sets of data differ considerably in their order of magnitude (i.e. the amount of rain gauge data are 100 while the radar data are 27390 ); (c) the different spatial distribution of the data from the two sources (i.e. the rain gauges data are randomly distributed while the radar data are radially distributed); and (d) the inherent limitations of the algorithm of IDW of the graphical package.

\section{Conclusions}

In the present study, the spatio-temporal evolution of the case of cyclogenesis over Cyprus area on 6 November 2005 is studied. The cyclogenesis is evident right after the passage of a pre-existing frontal depression on 4 November and with the merging of two upper lows to the west of Cyprus. The dynamics of the troposphere contributed to the development of convective weather phenomena that resulted in local flooding. The thermodynamic indices reveal the existence of instability, some of them suggesting thunderstorms and hail. The analysis adopted here covers a wide range of aspects related to flash floods and can shed light on the evolution of such hazardous events. Such analysis is of both diagnostic and prognostic significance.

Acknowledgements. This study was undertaken within the framework of project "Flash" which is funded by the European Union (Sixth Framework Programme, Contract No. 036852).

Edited by: A. Mugnai

Reviewed by: one anonymous referee

\section{References}

El-Fandy, M. G.: Barometric Lows of Cyprus, Q. J. Roy. Meteor. Soc., 72, 291-306, 1946.

Einfalt, T. and Michaelides, S.: Quality control of precipitation data. in: Precipitation: Advances in measurement, estimation and prediction, edited by: Michaelides, S., Springer-Verlag, ISBN:978-3-540-77654-3, 101-125, 2008.

Flash project: http://flash-eu.tau.ac.il/, access: 6 June 2008.

Gabella, M., Michaelides, S., and Perona, G.: Preliminary comparison of TRMM and ground-based precipitation radars for a European test site, Int. J. Remote Sens., 26, 997-1006, 2005.

Gabella, M., Joss, J., Perona, G., and Michaelides, S. : Range Adjustment for Ground-Based Radar, Derived With the Spaceborne TRMM Precipitation Radar, IEEE T. Geosci. Remote Sens., 44, 126-133, 2006.

Kallos, G. and Metaxas, D. A.: Synoptic processes for the formation of Cyprus lows, Rivista Meteorologia Aeronautica XL (2-3), 121-138, 1980.

Michaelides, S., Nicolaides, K., and Karacostas, T.: Statistical characteristics of the cold season depressions over the area of Cyprus, Meteorologický asopis 7, 61-66, 2004.

Nicolaides, K.: Synoptic and dynamic study of the depression cases affected the wider area of Cyprus during cold months, $\mathrm{PhD}$ thesis, Aristotelian University, Thessaloniki, Greece, 2005 (in Greek).

Nicolaides, K., Michaelides, S., and Karacostas, T.: Spatial distribution of some dynamic parameters during the evolution of selected depressions over the area of Cyprus, Int. J. Climatol., 24, 1829-1844, 2004.

Orphanou, A., Savvidou, K., Nicolaides, K., Michaelides, S., and Theodorou, A.: Thermodynamic indices over the area of Cyprus. Proceedings of the 8th European Conference on Applications of Meteorology, San Lorenzo de El Escorial, Spain, 2007.

University of Wyoming: http://weather.uwyo.edu/upperair/ sounding.html, access: 6 June 2008. 